\title{
Yükseköğretimde Her Yerde Öğrenmenin Akademik Başarı ve Motivasyona Etkisi
}

\author{
Fatih ERDOĞDU ${ }^{1}$, Sami ŞAHİN ${ }^{2}$ \\ ${ }^{1}$ Karadeniz Teknik Üniversitesi, Bilgisayar ve Öğretim Teknolojileri Eğitimi Bölümü \\ ${ }^{2}$ Gazi Üniversitesi, Bilgisayar ve Öğretim Teknolojileri Eğitimi Bölümü \\ fatiherdogdu67@gmail.com, sami@gazi.edu.tr \\ (Geliş/Received: 09.06.2016; Kabul/Accepted: 14.08.2016)
}

DOI: $10.17671 /$ btd.98182

\begin{abstract}
$\ddot{O}_{z} \boldsymbol{e t}-\mathrm{Bu}$ araştırmada, her yerde öğrenmenin üniversite düzeyinde bir uygulaması yapılarak sonuçlar, ders başarısı ve derse yönelik motivasyon açısından değerlendirilmiştir. Araştırmada nicel araştırma yöntemlerinden deneysel desen kullanılmıştır. Trabzon ilinde, sınıfında uygulama için yeterli internet altyapısı olan bir üniversitede, Bilgisayar ve Öğretim Teknolojileri Eğitimi Bölümü 2.sınıf İnsan Bilgisayar Etkileşimi dersi kapsamında gönüllü öğrencilerinden oluşan bir örneklem seçilmiştir. Katılımcılar deney grubu ve kontrol grubu olarak ikiye ayrılmıştır. Gruplar 21 'er kişiden oluşmaktadır. Deney grubuna 4 hafta boyunca her yerde öğrenme etkinlikleri destekli öğretim uygulanırken kontrol grubuna aynı öğretim her yerde öğrenme desteği olmadan sağlanmıştır. Araştırma sonucunda her yerde öğrenmenin uygulandığı öğrenci grubunun akademik başarıları ve motivasyon puanları diğer gruba göre anlamlı farklılık gösterdiği sonucuna ulaşılmıștır. Ayrıca, araştırma süreci ve sonuçları dikkate alınarak uygulamaya ve araştırmaya yönelik bir takım önerilerde bulunulmuştur. *Dikkat: Bu çalışma, ikinci yazarın danışmanlığında birinci yazar tarafından yüksek lisans tezinden üretilmiştir.
\end{abstract}

Anahtar Kelimeler - Her yerde öğrenme, akademik başarı, motivasyon, insan bilgisayar etkileşimi

\section{The Effect of Ubiquitous Learning on Academic Achievement and Motivation in Higher Education: The Case of Human-Computer Interaction Course}

\begin{abstract}
In this study, ubiquitous learning method was implemented in higher education and the results were analyzed in terms of course achievement and motivation for the course. The study was conducted through experimental research design. The sample of the study is undergraduate students who are in their second year in a higher education institution having sufficient internet infrastructure within the classrooms in Trabzon province, are registered to HumanComputer Interaction course at Computer Education and Instructional Technology Department, and are voluntary to participate in the study. The participants are divided into two as experimental and control group. Each group has 21 students. While the instruction supported with ubiquitous learning activities was conducted in the experimental group throughout 4 weeks, the same instruction without ubiquitous learning activities was conducted in the control group. According to the study results, the academic achievement and motivation scores of the student group for which ubiquitous learning was implemented is significantly different than the control group. In addition, as considering research process and results, it was made recommendations for future research and implementation. *CRITICAL: This study was conducted by the first author as a part of a master's thesis under the supervision of the second author.
\end{abstract}

Keywords - Ubiqutious learning, academic achievement, motivation, human computer interaction

\section{GİRIŞ (INTRODUCTION)}

Mobil teknolojiler sayesinde, bilişim teknolojileri seyahat esnasında bile kullanım alanı bulmanın yanı sıra eğitimöğretimde de etkili bir şekilde kullanılmaya başlanmıştır. $\mathrm{Bu}$ teknolojiler sayesinde öğrenciler, bulundukları ortam ya da bu ortamdaki nesneler ile ilgili doğrudan ortamdan veya ortamdaki nesnelerden bilgiyi anında elde ederek her yerde öğrenme imkânı bulabilmektedirler [1].

Literatür incelendiğinde, bilişim teknolojilerini takiben yeni pedagojik kavramların da ortaya çıktığı görülmektedir. İnternet teknolojilerinin yaygınlaşması ile e-öğrenme; mobil teknolojilerin ortaya çıkması ile m- 
öğrenme; tüm bunlara ek olarak algılayıcı teknolojilerin yaygınlaşması ile beraber her yerde öğrenme kavramı ortaya çıktığı görülmektedir $[2,3,4,5,6]$. Her yerde öğrenme; herhangi bir kişinin, herhangi bir yerden, herhangi bir zamanda ve anında bilgiye ulaşabilmesi anlamına gelmektedir [7]. Ayrıca, bir diğer tanım ise doğru zamanda, doğru yerde ve doğru içerikle öğrenme olarak ifade edilmesidir [8].

Her yerde öğrenme, Mark Weiser'in 1991 y1lında ortaya koyduğu "her yerde bilişim" kavramına dayanan bir öğrenme çeşididir [9]. Her yerde bilişim, teknolojinin günlük hayata gömülü olması ve bu teknolojinin sessizce çalışması anlamına gelmektedir [10]. Otobüs duraklarında, otobüsün güzergâhını, kaç dakika içinde hangi durakta olacağını gösteren bilgisayarlar; müzelerde, sergilenen nesneler hakkında bilgiye mobil cihazlarımızla ulaşabileceğimiz algılayıcı teknolojiler, teknolojinin günlük yaşantımıza gömülü olduğunu gösteren örneklerdir. Görünmez teknoloji olarak da nitelendirilen bu teknolojiler, öğrenenlerin dikkatlerini dağıtmadan ve doğal öğrenme ortamını bozmadan çalışan, her yerde öğrenme teknolojileri olarak adlandırılırlar [10]. Örneğin; RFID etiketleri, GPS, QR kod etiketleri vb. algılayıcı teknolojiler, her yerde öğrenmenin gerçekleşmesini sağlayan teknolojilerdir [3]. Bu teknolojilerin bulunduğu ortamda birey, mobil cihazları ve internet teknolojisini kullanarak elde etmek istediği bilgiye anında, doğal davranışını bozmadan kısaca zahmetsiz bir şekilde ulaşabilmektedir.

Her yerde öğrenmenin öğretim ortamına sağladığ yenilikler ve faydalar aşağıdaki başlıklarda toplanabilir [11].

Devaml: Tüm öğrenme süreçlerinin devamlı kaydedilmesi

Erișilebilir: Herhangi bir yerden; doküman, bilgi ve videolara ulaşabilmesi

Anında: Nerede olursa olsun öğrenenlerin bilgiye anında ulaşabilmesi ve problemleri hızlıca çözebilmesi

Etkileșimli: Öğrenenler eş-zamanlı ve eş-zamansız olarak uzman, öğretmen ve arkadaşlarıyla etkileşime geçebilmesi

\section{Bütünleşik: Öğrenme günlük yaşantı ile bütünleşiktir}

\section{Uyarlanabilir: Öğrenenlerin doğru bilgiye doğru yerden} ulaşabilmesi

Yukarıda faydalarından bahsedilen her yerde öğrenmenin en önemli özelliklerinden birinin bağlam farkındalığ olduğu ifade edilmektedir [2]. Bağlam farkındalığı, öğrenme ortamında, öğrenenlerin öğrenme koşullarını (konum, hareket, hava durumu, zaman, vb.) belirlemeleri olarak ifade edilmektedir [6]. Bu noktada, her yerde öğrenmede önemli olan öğrencinin bulunduğu ortam ile ilgili öğrenmeyi gerçekleştirmesidir [6]. Örneğin, öğrenci bulunduğu ortam ya da etrafindaki nesneler ile ilgili bilgiye RFID, QR kod, GPS gibi algılayıcı (sensör) teknolojiler sayesinde anında ve kolaylıkla ulaşabilmektedir. Bağlam farkındalığı, her yerde öğrenmeyi m-öğrenmeden ayıran en belirgin özellik olarak görülmektedir. Eğer bağlam farkındalığı özelliği yok ise her yerde öğrenme gerçekleşmemektedir. Bağlam ile ilişkili olarak öğrenmelerini gerçekleşmeye yönelik etkinliklerin öğrencilerin kalıcı bir şekilde öğrenmelerine ve öğrenme sürecinde aktif olarak katıldıklarından dolayı motivasyonlarına yardımcı olabileceği düşünülmektedir.

Her yerde öğrenmenin öğrencilerin akademik başarı, tutum ve motivasyonlarına yönelik olumlu bir etkisinin olduğu yapılan araştırma sonuçlarından görülebilmektedir $[5,12,13,14]$. Araştırmalar incelendiğinde daha çok sınıf dışı etkinliklere dayalı etkinlikler kapsamında gerçekleştirildikleri görülmektedir. Buna karşın sınıf için uygulamaların sınırlı olduğu görülmüştür. Araştırmaların çoğunlukla ilköğretim seviyesinde uygulandığ 1 [12, 15, 3] ve çoğunlukla algılayıcı teknoloji olarak RFID etiketleri kullanıldığ 1 dikkat çekmektedir [5, 6]. RFID etiketlerinin ve kullanılan PDA'ların pahalı oluşu sebebi ile bu araștırmada QR kodlar ve akıllı telefonlar kullanılmıştır. $\mathrm{Bu}$ teknolojilerin ulaşılabilir olması ve öğrenciler için ek bir zahmet getirmemesi de ayrica bir avantaj olarak değerlendirilebilir.

$\mathrm{Bu}$ araştırmada, her yerde öğrenme teknolojilerinden olan akıllı telefon, tablet ve QR kod etiketleri İnsan Bilgisayar Etkileşimi dersinde kullanılmıştır. $\mathrm{Bu}$ kapsamda araştırmada her yerde öğrenmenin akademik başarıya ve motivasyona etkisinin incelenmesi amaçlanmıştır.

\section{YÖNTEM (METHOD)}

\subsection{Araştırma Deseni (Research Design)}

Araştırmada ön-test son-test kontrol gruplu deneysel desen kullanılmıştır.

\section{2. Örneklem (Sample)}

Trabzon ilinde internet altyapısı mevcut olan bir öğretim kurumunda, üniversite 2. sınıf İnsan Bilgisayar Etkileşimi dersi gönüllü öğrencilerinden oluşan bir örneklem seçilmiştir. Katılımcılar deney grubu ve kontrol grubu olarak ikiye ayrılmıştır. Deney ve kontrol grubu öğrencileri de 21 'er kișiden oluşmaktadır. Deney grubundaki öğrencilere 4 hafta (12 ders saati) boyunca her yerde öğrenme etkinlikleri ile desteklenen öğretim uygulanırken kontrol grubunda ise aynı ders bu sunumlar üzerinden dersi anlatmıştır.

\subsection{Veri Toplama Araçları (Data Collection Tools)}

Deney ve kontrol grubu öğrencilerinin akademik başarılarını belirlemek amacıyla Kullanılabilirlik 
Çalışmada deney ve kontrol gruplarının akademik başarı ön test puanlarının dağılım durumlarını göstermek için çarpıklık ve basıklık katsayısı incelenmiştir. Deney grubu için çarpıklık ve basıklık katsayısı sırasıyla 0,042 ve 0,384 ; kontrol grubu için sirasiyla $-0,805$ ve 0,421 'dir. Deney grubu akademik başarı son test puanları için çarpıklık ve basıklık katsayısı sırasıyla $-0,008$ ve $-1,017$; kontrol grubu için sırasıyla 0,191 ve $-0,754$ 'tür. Deney grubu öğrencilerinin motivasyon ölçeği puanları için çarpıklık ve basıklık katsayısı sırasıyla $-0,317$ ve $-0,405$; kontrol grubu öğrencilerinin motivasyon ölçeği puanları için ise sırasiyla $-0,224$ ve $-0,228$ 'dir. Deney ve kontrol grubu öğrencilerinin akademik başarı ön test ve son test puanları ile motivasyon ölçeği puan dağılımları varyansların eşitliği varsayımlarını sağlamıştır $(p>0,05)$.

Akademik başarı testinin yanında Öğretim Materyali Motivasyon Ölçeği de uygulanmıştır. Öğretim Materyali Motivasyon Ölçeği 1987 yılında Keller tarafından geliştirilmiş ve Kutu ve Sözbilir tarafından 2011 yılında Türkçeye uyarlanmıştır. Ölçek 5'li likert olarak derecelendirilmiştir [17]. Ölçeğin uyarlama çalışması Atatürk ve Erzincan Üniversiteleri Eğitim Fakültelerinden 262 öğrenci üzerinde yapılmıştır. Öğretim materyallerinin derse yönelik motivasyona etkisini ortaya koymak için tasarlanan ölçek ARCS öğretim tasarımı modeli temel alınarak hazırlanmıştır. Öğretim Materyali Motivasyon Ölçeğinin Türkçeye çevrilmiş halinin Cronbach alfa güvenirlik katsayısı 0,83 'tür.

\subsection{Verilerin Toplanmast ve Analizi ( Data Collection and Analysis)}

Araştırma, üniversite 2. Sınıf Bilgisayar ve Öğretim Teknolojileri Eğitimi Bölümü İnsan Bilgisayar Etkileşimi dersinde uygulanmıştır. İlk olarak, belirlenen üniteyi kapsayan konular için her yerde öğrenme teknolojilerinin kullanılacağı ders etkinlikleri hazırlanmıştır. Uygulama öncesi, deney grubu ve kontrol grubu öğrencilerine konu ile ilgili akademik başarılarını ölçmek için ön test uygulanmıştır. Daha sonra, uygulama bitiminin hemen ardından deney ve kontrol grubu öğrencilerine akademik başarıları için son test ve derse yönelik motivasyonlarını belirlemek için motivasyon ölçeği uygulanmıştır. Akademik başarı testi ve motivasyon ölçeğinden elde edilen sonuçlar SPSS 17.0 istatistik programı ile analiz edilmiştir.

Deney ve kontrol gruplarının başarıları arasında anlamlı fark olup olmadığına bakmak için bağımsız örneklemler için t testi uygulanmıştır. Ayrıca, ön test ve son testleri arasındaki farkı incelemek amacı ile bağımlı örneklemler için t testi uygulanmıştır. Bunlara ek olarak, motivasyon ölçeği ile deney ve kontrol gruplarından toplanan veriler yine bağımsız örneklemler için $\mathrm{t}$ testi kullanılarak analiz edilmiştir.

Parametrik testler için gerekli olan normallik varsayımı puanların çarpıklık ve basıklık katsayısına bakılarak değerlendirilmiştir [18]. Çarpıklık ve basıklık katsayılarının -1 ile +1 arası olması puanların normal dağıldığını varsaymak için yeterli görülmektedir [19].
Deney ve kontrol grubu öğrencilerinin araştırma öncesindeki akademik başarı puanları arasında anlamlı deney ve kontrol grubu öğrencilerinin akademik başarı ön test puanları arasında anlamlı bir farklılık bulunamamıştır $(\mathrm{p}>0,05)$. Bu durum, iki grubun da konuyla ilgili ön bilgilerinin eşit olduğunu göstermektedir. Ayrıca, kontrol grubu öğrencilerin ön test puan ortalamaları $(\overline{\bar{X}}=11,85)$ ile deney grubu ön test puan ortalamaları $(\bar{X}=12,61)$ yaklaşık olarak birbirine eşittir.

\subsection{Etkinlik Uygulama Süreci (Process of Activiy Implementation)}

Şekil 1'de her yerde öğrenme etkinliklerin uygulama süreci gösterilmiştir:

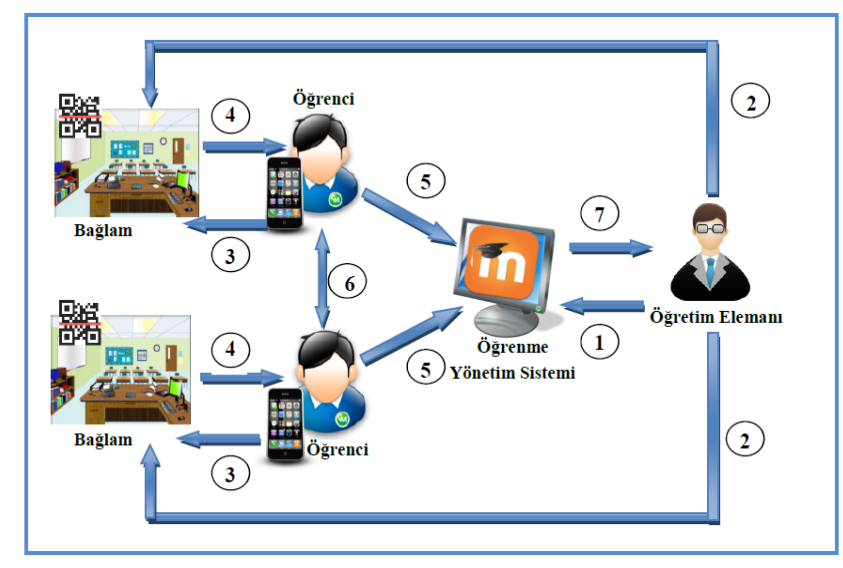

Şekil 1. Etkinlik uygulama süreci

(The process of implementing activity)

Şekil 1'de, 1 ve 7 arasında numaralandırılmış aşamalar kısaca şöyledir:

1. Öğretim elemanı, oluşturmuş olduğu e-içeriği (video, quiz, animasyon vb.) öğrenme yönetim sistemine uygulama öncesinde ekler ya da bu sistemde oluşturur.

2. Öğretim elemanı, oluşturduğu bu içeriklerin linklerini nesneye bu etiketleri yapıştırır. fark olup olmadığı $\mathrm{t}$ testi ile incelenmiştir. Sonuç olarak QR kod etiketlerine gömer ve ortamda bulunan 
3. Öğrenci, uygulanma esnasında mobil cihazın kamerası ile QR kod etiketini taratır.

4. Öğrenci, QR kod etiketini tarattıktan sonra karşısına çıkan linki tıklar.

5. Öğrenci, linke tıkladığında uygulama öncesi öğretim elemanının yüklediği öğrenme yönetim sistemindeki bilgiye anında ulaşır.

6. Öğrenciler, öğrenme yönetim sistemi aracılı̆̆ birbirleri ile etkileşim haline geçebilirler.

7. Öğretim eleman1, öğrenme yönetim sisteminde kaydedilen öğrenci bilgilerini kontrol edebilir ve daha sonrası için değerlendirme işleminin gerçekleştirebilir.

Dört haftalık uygulama sürecinde her yerde öğrenme destekli öğretim Şekil 1'de gösterildiği gibi deney grubuna uygulanmıştır. Uygulama sürecinde toplam 11 her yerde öğrenme destekli etkinlikler yapılmıştır. Her yerde öğrenme destekli öğretim etkinliklerinden birine örnek Şekil 2'de gösterilmiştir:

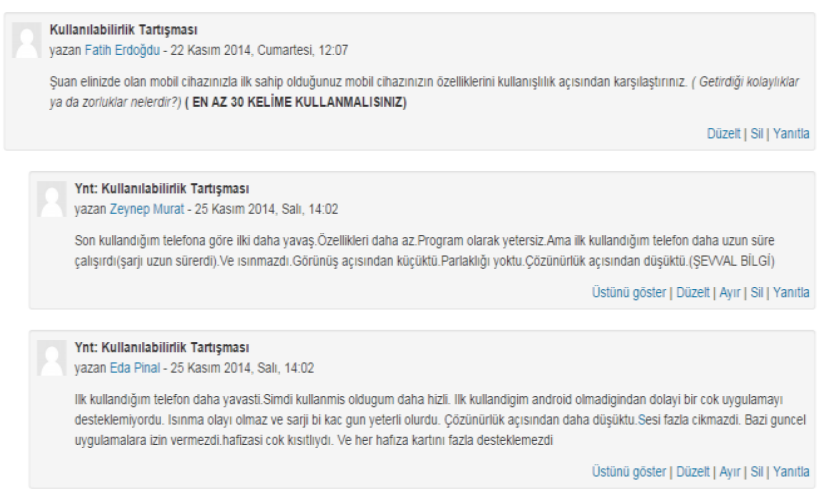

Şekil 2. Etkinlik örneği

(Activity example)

Şekil 2'de gösterilen etkinlikte sınıfın uygun bir yerine ilk olarak QR kod yerleştirilmiştir. Öğrenciler daha sonra cep telefonları ile QR kodu taratmış ve ardından şu anki cep telefonu ile ilk telefonunun özelliklerini kullanışlılık açısından tartışmaları istenmiştir. Böylece bağlamda bulunan nesne (ellerindeki cep telefonları) ile ilgili öğrenmelerini gerçekleştirmeleri sağlanmıştır.

12 haftalık uygulama sürecinde öğrencilere her yerde öğrenme destekli 11 etkinlik uygulanmıştır. Bu etkinlikler kullanılabilirlik ünitesine ait olan dokuz kazanıma yönelik olarak tasarlanmıştır. Bu kazanımlar şu şekildedir;

- Kullanılabilirliğin ne olduğunu açıklar.

- Kullanılabilirliğin faydalarını sıralar

- Kullanılabilirlik derecesi, etkililik, verimlilik ve memnuniyet ilişkisini açıklar.

- Bilişsel psikolojinin kullanılabilirlik ile olan ilişkisini ifade eder.

- Kullanılabilirliğin ana bileşenlerini açıklar.

- Kullanılabilirlik tür ve yaklaşımları örnekler vererek açıklar.

- Kullanılabilirlik çalışmalarında izlenmesi gereken adımları sıralar.
- Kullanılabilirlik yaklaşımlarının avantaj ve dezavantajlarını sıralar.

- Kullanılabilirlik alanında kullanılan teknolojileri açıklar.

Her etkinlikte öğrenciler cep telefonları ile sınıf ortamında belirli yerlere yapıştırılan QR kodları taratıp etkinliği uygulamıştır. $\mathrm{Bu}$ etkinlikler öğrencilerin bulundukları ortamdaki nesnelerin kullanılabilirliğine yönelik ve kazanımlar çerçevesinde uygulanmıştır. Örneğin, sınıf ortamında bulunan video konferans cihazına yapıştırılan QR kod ile bir etkinlik gerçekleştirilmiştir. Ayrıca, şuan ki cep telefonları ile ilk telefonlarının kullanışlılık özelliklerinin QR kod taratılarak tartışmaları istenmiş ve sınıfta gönüllü iki öğrenciye canlandırma yapılarak QR kodlar taratılmış ve kullanılabilirlik aşamalarının yazılması istenmiştir. Bunlara ek olarak, kullanılabilirlik ile ilgili bir fotoğraf dağıtılmış ve üzerindeki QR kod taratılarak soruların çözülmesi sağlanmış ve bu etkinliklerin yanında gönüllü öğrencilere canlandırma yaptırılarak kullanılabilirlik çalışması öncesinde nelerin yapılabileceği gösterilmiş ve diğer öğrencilerin ise yapıştırılmış olan QR kod taratılarak bu aşamalar hakkında tartışmaları istenmiştir. $\mathrm{Bu}$ etkinlikler için sınıf ortamında bulunan nesnelere (video konferans cihazı, canlandırmanın yapıldığı masanın üstü, eski bir cep telefonu, fotoğrafın üstü vb.)

\section{BULGULAR (RESULTS)}

\subsection{Her Yerde Öğrenme Destekli Etkinliklerin Akademik} Başarlya Etkisi ( The Effect of Ubiquitous Learning Supported Activies on Academik Achievement)

İlk olarak, deney grubu öğrencilerinin akademik başarı ön test ve son test puanları arasında anlamlı bir fark olup olmadığını göstermek için bağımlı t testi kullanılmıştır (Tablo 3).

Tablo 3. Deney grubu akademik başarı ön-test ve son-test puanları bağımlı $\mathrm{t}$ testi sonuç tablosu

(Dependent $t$ test results between academic achievement pre-test and

\begin{tabular}{|l|c|c|c|c|c|c|}
\hline Puan & $\mathrm{N}$ & $\overline{\bar{X}}$ & Ss & t & df & $\mathrm{p}$ \\
\hline $\begin{array}{l}\text { Öntest } \\
\text { Puan1 }\end{array}$ & 21 & 12,61 & 3,30 & & & \\
\hline $\begin{array}{l}\text { Sontest } \\
\text { Puan1 }\end{array}$ & 21 & 17,95 & 2,43 & $-5,60$ & 20 & 0,00 \\
\hline
\end{tabular}

Bağımlı t testi sonucuna göre deney grubu öğrencilerinin uygulama öncesi akademik başarı durumları ile uygulama sonrası akademik başarı durumları arasında anlamı bir fark vardır $(\mathrm{p}<0,05)$. Bu durum, uygulamanın deney grubu öğrencilerinin akademik başarılarını artırdığının göstergesidir. Daha sonra, deney ve kontrol grubu öğrencilerin araştırma sonrasındaki akademik başarı puanları arasında anlamlı fark olup olmadığını ortaya koymak için bağımsız $t$ test analizi yapılmıştır (Tablo 4). 
Tablo 4. Deney ve kontrol grubu akademik başarı son-test puanları bağımsız t testi sonuç tablosu

(Academic achievement post-test point independent $t$ test results table between experimental and control group)

\begin{tabular}{|l|c|c|c|c|c|c|}
\hline Gruplar & $\mathrm{N}$ & $\overline{\mathrm{X}}$ & $\mathrm{Ss}$ & $\mathrm{t}$ & $\mathrm{df}$ & $\mathrm{p}$ \\
\hline $\begin{array}{l}\text { Kontrol } \\
\text { Grubu }\end{array}$ & 21 & 15,42 & 3,02 & 2,97 & 40 & 0,005 \\
\hline $\begin{array}{l}\text { Deney } \\
\text { Grubu }\end{array}$ & 21 & 17,95 & 2,43 & & \\
\hline
\end{tabular}

Deney ve kontrol gruplarının akademik başarı son test puanları arasında anlamlı farklılık bulunmuştur $(\mathrm{p}<0,05)$. $\mathrm{Bu}$ sonuca göre uygulama yapılan deney grubu öğrencilerinin kontrol grubu öğrencilerine göre akademik başarılarının daha yüksek olduğu görülmektedir.

\subsection{Her Yerde Öğrenme Destekli Etkinliklerin} Motivasyona Etkisi ( The Effect of Ubiquitous Learning Supported Activies on Motivation)

Deney ve kontrol grubu öğrencilerinin motivasyon ölçeğine vermiş oldukları tüm cevapların puanları arasında anlamlı farkın olup olmadığını ortaya koymak için bağımsız t testi uygulanmıştır (Tablo 5).

Tablo 5. Deney ve kontrol grubu motivasyon ölçeği bağımsız $t$ test sonuç tablosu

(Motivation scale independent $t$ test results table between experimental and control group)

\begin{tabular}{|l|c|c|c|c|c|c|}
\hline Gruplar & $\mathrm{N}$ & $\overline{\mathrm{X}}$ & $\mathrm{Ss}$ & $\mathrm{t}$ & $\mathrm{df}$ & $\mathrm{p}$ \\
\hline $\begin{array}{l}\text { Kontrol } \\
\text { Grubu }\end{array}$ & 21 & 3,59 & 0,439 & \multirow{2}{*}{$-3,18$} & 40 & 0,003 \\
\cline { 1 - 5 } $\begin{array}{l}\text { Deney } \\
\text { Grubu }\end{array}$ & 21 & 3,95 & 0,274 & -303 \\
\hline
\end{tabular}

Her yerde öğrenme etkinlikleri uygulanan öğrencilerin motivasyon ölçeğine vermiş oldukları cevapların puanları ile her yerde öğrenmenin uygulanmadığı diğer grubun puanları arasında anlamlı bir fark bulunmaktadır $(p<0,05)$. Bu sonuç, deney grubu öğrencilerinin İnsan Bilgisayar Etkileşimi dersine yönelik motivasyonlarının, kontrol grubu öğrencilerinin motivasyonlarından daha yüksek olduğunu göstermektedir.

\section{SONUÇ ve ÖNERILER (CONCLUSION and SUGGESTIONS)}

\subsection{Sonuçlar ( Conclusions)}

$\mathrm{Bu}$ araştırmada her yerde öğrenme, yükseköğretim seviyesinde "İnsan Bilgisayar Etkileşimi” dersinde "Kullanılabilirlik" ünitesi kapsamında uygulanmıştır. Uygulama öncesi öğrenciler deney ve kontrol grubu olarak ikiye ayrılmışlardır. Deney grubu öğrencilerine 12 ders saati boyunca her yerde öğrenme etkinlikleri ile desteklenen öğretim yapılmış: kontrol grubu öğrencilerine ise aynı ders saati boyunca her yerde öğrenme etkinlikleri kullanılmadan öğretim yapılmıştır. Uygulama öncesi deney ve kontrol grubu öğrencilerinin "Kullanılabilirlik" ünitesi için akademik başarı düzeyleri eşit olarak bulunmuştur.

Daha sonra deney gurubu öğrencilerinin uygulama öncesi ve sonrası akademik başarı düzeyleri karşılaştırılmıştır. $\mathrm{Bu}$ karşılaştırma sonucunda, öğrencilerinin uygulama sonrasındaki akademik başarı düzeylerinin arttı̆̆ görülmüştür. Benzer şekilde her yerde öğrenmenin uygulandığı öğrencilerin uygulama sonrası akademik başarılarının arttığı ve öğrenme zamanını düşürdüğü bulunmuştur [3]. Akademik başarılarının olumlu yönde etkilenmesi ögrrencilerin derse olan tutumlarını da olumlu yönde etkileyebileceği düşünülmektedir. Böylece öğrenci hem derste başarılı olurken hem de derse olan olumsuz düşüncesinin azalabileceği öngörülmektedir.

Ayrıca her yerde öğrenmenin uygulandığı deney grubu ile kontrol grubunun uygulama sonrası akademik başarıları karşılaştırılmıştır. $\mathrm{Bu}$ karşılaştırma sonucunda öğrencilerinin akademik başarıları deney gurubu lehine istatistiksel olarak anlamlı çıkmıştır. Benzer olarak her yerde öğrenme uygulanan ve uygulanmayan öğrencilerin akademik başarılarının karşılaştırıldığı çalışmalarda karşılaştırma sonucunda her yerde ögrenme uygulanan öğrencilerin daha başarılı olduğu tespit edilmiştir [5]. Bunun sebebi her yerde öğrenme destekli etkinliklerinin öğrencilerin derse olan dikkati çekmesinden kaynaklandığı düşünülebilir. Ayrıca, derse olan dikkatin çekilmesi öğrencinin derse karşı motivasyonunu da olumlu yönde etkileyebileceği düşünülmektedir.

Bunlara ek olarak araştırma kapsamında her yerde öğrenme uygulanan ve uygulanmayan grupların motivasyon durumları da incelenmiştir. Araştırmanın sonucuna göre her yerde öğrenmenin uygulandığ 1 öğrencilerin motivasyonları diğer gruba göre daha yüksektir. Yapılan benzeri araştırmalarda her yerde öğrenmenin uygulandığ bulduğunu, kullanılan teknolojilerin ilgilerini çektiğini ve bu sebeple de motivasyonlarının yüksek olduğunu belirtilmişlerdir [12].

Yapılan bu araştırmada, her yerde öğrenme destekli etkinliklerin akademik başarı ve motivasyon gibi öğrenme çıktıları üzerinde olumlu bir etkisinin olduğu sonucuna ulaşılmıştır. Sözel ağırlıklı ve daha çok bilgiye dayalı ders içeriğine sahip derslerde öğrencilerin sıkıldığı, bu sebepten dolayı konuyu anlamakta güçlük çektiği bilinmektedir. Her yerde öğrenme destekli etkinlikler uygulanarak bu olumsuz durumun giderilmesine katk1 sağlanabilir.

\section{KAYNAKLAR (REFERENCES)}

[1] P.-S. Tsai, G.-J. Huwang, C.-C. Tsai, "Development a survey for assessing preferences in constructivist context-aware Ubiquitous learning environments" Journal of Computer Assisted Learning, 250264,2011 . 
[2] Y. Huang, P. Chiu, T. Liu ve T. Chen, "The design and implementation of a meaningful learning-based evaluation method for ubiquitous learning" Computer \& Education, 57, 2291-2302, 2011.

[3] C.-C. Chen ve, T.-C. Huang, "Learning in a u-museum: Developing a context-aware ubiquitous learning environment", Computer \& Education, 59, 873-883, 2012.

[4] H.-Y. Jeong ve B.-H. Hong, “A pratical use of learning system using user preference in ubiquitous computing environment". Multimed Tools Appl., 64, 491-504, 2013.

[5] Y. Liu, (2009). "A context-aware ubiquitous learning environment for language listening and speaking", Journal of Computer Assisted Learning, 25, 515-527, 2009.

[6] W.-C. Shih, , S.-S. Tseng, , C.-C. Yang, C.-Y. Lin ve T. Liang, "A Folksonomy-based guidance mechanism for context-aware ubiquitous learning: A case study of Chinese scenic poetry appreciation activities", Educational Technology \& Society, 15(1), 90-101, 2012.

[7] W. Junqi, L. Yumei ve L. Zhibin, "Study of Instructional design in Ubiquitous Learning", 2010 Second International Workshop on Education Technology and Computer Science, IEEE, 2010.

[8] S. Shih, B. Kuo ve Y. Liu, (2012). "Adaptively Ubiquitous Learning in Campus Math Path", Educational Technology\&Society, 15(2), 298 308,2012 .

[9] M. Weiser, (1991). "The computer for the 21st century", Scientific american,265(3), 94-104, 1991.

[10] W. Ng, H. Nicholas, S. Loke ve T. Torabi, "Designing Effective Pedagojical Systems for Teaching and Learning with Mobile and Ubiquitous Devices", Multiplatform E-Learning Systems and Technologies, Editör: T. Tiong (s. 42-56). Information Science Reference, New York, 42-56, 2010.

[11] O.K. Boyinbode ve K.G. Akintola, "Effecting E-learning with Ulearning Technology in Nigerian EducationSystem", The Pasific Journal of Science and Technology, 10(1), 204-210, 2009.

[12] H. Peng, P.-Y. Chuang, G.-J. Hwang, H.-C. Chu, T.-T. Wu ve S.-X. Huang, "Ubiquitous Performance-support System as Mindtool: A case Study of Instructional Decision Making and Learning Assistant", Educational Technology \& Society, 12(1), 107-120, 2009.
[13] T.-Y. Liu, T.-H. Tan ve Y.-L. Chu, "Outdoor Natural Science Learning with an RFID-supported Immersive Ubiquitous Learning Environment", Educational Technology \& Society, 12(4), 161-175, 2009

[14] G.-J. Hwang, H.-C. Chu, Y.-S. Lin ve C.-C. Tsai, "A knowledge acquisition approach to developing Mindtools for organizing and sharing differentiating knowledge in a ubiquitous learning environment", Computer \& Education, 57, 1368-1377, 2011

[15] J.-L. Shih, H.-C. Chu, G.-J. Hwang ve Kinshuk, "An investigation of attitudes of students and teachers about participating in a contextaware ubiquitous learning activity", British Journal of Educational Technology, 42(3), 373-394, 2011

[16] K. Çăğltay, İnsan Bilgisayar Etkileşimi ve Kullanılabilirlik Mühendisliği: Teoriden Pratiğe. ODTÜ Yayıncılık, Ankara,Türkiye, 2011.

[17] H. Kutu, ve M. Sözbilir , "Öğretim Materyalleri Motivasyon Anketinin Türkçeye Uyarlanması: Güvenirlik ve Geçerlik Çalışması", Necatibey Eğitim Fakültesi Elektronik Fen ve Matematik Eğitimi Dergisi, 5(1), 292-312, 2011.

[18] Ş. Büyüköztürk. Sosyal Bilimler İçin Veri Analizi El Kitabı, Pegem Yayınc1lık, Ankara,2014. 